\title{
A STUDY OF IMAGE-BASED ELEMENT CONDITION INDEX FOR BRIDGE INSPECTION
}

\author{
*R. S. Adhikari ${ }^{1}$, O. Moselhi ${ }^{2}$ and A. Bagchi ${ }^{3}$ \\ ${ }^{1}$ Department of Building, Civil, and Environment Engineering, Concordia University, \\ Montreal, Canada, H3G 1M8; PH (514) 848-2424 ext. 7144;* Corresponding author \\ (ram_adhiakri91@yahoo.com)
}

${ }^{2}$ Department of Building, Civil, and Environment Engineering, Concordia University, Montreal, Canada, H3G 1M8; PH (514) 848-2424 ext.3190; email: (moselhi@encs.concordia.ca)

${ }^{3}$ Department of Building, Civil, and Environment Engineering, Concordia University, Montreal, Canada, H3G 1M8; PH (514) 848-2424 ext. 3213; email: (abagchi@bcee.concordia.ca) 


\title{
A STUDY OF IMAGE-BASED ELEMENT CONDITION INDEX FOR BRIDGE INSPECTION
}

\begin{abstract}
This paper presents an innovative computer vision method for condition assessments of bridges with multiple defects in bridge elements using digital images. This work utilizes 3D model of existing bridges and overlays digital images on 3D model to simulate on-site visual inspection. The analysis of element condition index (ECI) of bridges requires information about the severity and extent of defects in elements. In general, ECI is evaluated manually during routine bridge inspection considering the severity of dominant defects. The evaluation of ECI with multiple defects needs to be addressed with consideration of dominant defect as well as the interaction among defects. However, Image-based quantification techniques largely depend on geometry of objects (i.e. shapes). Shape vectors of a given object change as they are translated, rotated, and scaled with different magnitudes. This work considers shape preserving algorithms such as, affine and projective transformation for proper image alignment. Semi-automated approach for detection and quantification of concrete distress such as cracks and spalling are considered for the defects analysis. The proposed methodology ensures the consistency in reporting ECI and eliminates the shortcoming of traditional approaches.
\end{abstract}

\section{KEYWORDS}

Digital Images, Visual Inspection, Condition Index, Distress types, 3D visualization

\section{INTRODUCTION}

Bridges are an integral part of a country's transportation infrastructure networks contributing to its economical and social development. So, it is necessary to maintain their functionality during design life of bridges. The functionality of bridges are affected many factors including aging, increased traffic loads, climatic changes, degree of pollutions, and deterioration of bridge components and many more to list. To ensure the safety of a bridge, regular inspections are required to identify the causes of deterioration and take necessary actions for maintenance and rehabilitation activities. Aging of bridges in Canada is a major problem as over $40 \%$ of all bridges are older than 50 years (Bisby and Briglio, 2004).

In practices, data collection for bridge inspection is performed by visiting the bridge sites (Federal Highway Administration, FHWA 1991). Information collected during the field visits serves as the primary source of input data for Bridge Management System (BMSs) software, such as PONTIS and BRIDGIT in $t$ he United States, DANBRO in Denmark, and BRIME in the European Community (Austroads 2002). The BMSs provide a common platform for data inventories, condition assessments, maintenance schedule, and budget allocation for bridges in a given road network system. One of the important modules of BMSs is condition assessment which provides overall information about elements considering types of distress present based on the inspection results. Today's BMSs require data information in a special format which describe the extent and severity of defects in structural members. The major tasks performed during a routine bridge inspection are two folds (U.S. Army Corps of Engineers, 1993). First is to inspect the physical condition of the bridge structures in terms of the extent and severity of defects. Second is to verify and update information about structures reported in last inspection. Traditionally, routine bridge inspection is 
carried out through visual inspection. Several limitations of visual inspection have been reported in literatures such as qualitative evaluation of defects (FHWA, 1991). Nevertheless, visual inspection is laborious, time consuming and influenced by subjective nature of decisions.

Recently, many attempts have been made to enhance the inspection process using new technologies such as digital image processing (Abudayyeh, Al Bataineh, Abdel-Qader, 2004). McRobbie, Lodge, a nd Wright (2007) found that digital images can be used for conducting offsite inspections of structures to a level of accuracy that is comparable with that achieved in-site. They also investigated 3D modeling of infrastructures that can simulate on-site visual inspection, and by automating these processes, the limitation of current practices of visual inspection can be improved (McRobbie, Woodward, and Wright, 2010). In this paper, a novel automated approach of retrieving element condition index based on digital images has been proposed and demonstrated. This approach considers common distress present in concrete structures and presents automated algorithms for distress identification and quantification. The developed algorithms ensure uniformity in data retrieval and thus eliminate potential subjective errors. The efficiency of developed tools is tested on real images concrete structures and the limitations are discussed to enhance the proposed methodology.

\section{BACKGROUND}

\section{Condition Ratings}

Condition ratings are defined as sets of visual pointers for use in routine inspection (Hearn and Shim, 1997). The outcomes of routine bridge inspection are reported as condition ratings. Condition states separate the nature and extent of damages in bridge elements, whereas condition ratings are used to explain the current condition of existing bridges as compared to as-built condition. Generally, condition ratings are expressed in ordinal numbers which provides qualitative information associated with objects such as 'excellent', 'good', 'fair', 'poor', and 'critical'. This kind of scale in describing the condition level in bridge element is very subjective and is difficult to apply in an automated system. Many jurisdictions have developed their own ways to describe different scales for condition states describing the health of bridge elements. However, the situation has improved with introduction of Bridge Management Systems (BMSs) to handle the infrastructure asset management issues. For example, the damage information used to determine the condition ratings are represented on a numerical scale that ranging from 0 (failed condition) to 9 (excellent condition) as used in National Bridge Inventory since 1970s (Recording 1988). PONTIS BMS uses the four-state and five-state condition rating scales developed for the commonly recognized elements. Considering the recent development towards automation, image-based automated prediction of condition state ratings was explored earlier by the authors using neural networks (Adhikari, Moselhi, Bagchi, 2012).

\section{Element Condition Index}

The estimation of automated prediction of condition ratings is essential for the evaluation of Bridge Condition Index (BCI) used for prioritization of maintenance and rehabilitation projects. It is measured on a scale of 0 to 100 where the numerical rating is derived from the inspection data. The value of 100 for the $\mathrm{BCI}$ of a bridge indicates that there is no defect, and a value of zero indicates that the bridge is unfit for use. However, in USA, Bridge Health Index (HI) developed by Roberts and Shepard (2001) is being used as an indicator for bridges prioritization which essentially serves the same purpose as BCI. The HI is defined as the ratio of current element value (CEV) to the total element value (TEV) of all the elements of a bridge where the CEV is the sum of the weighted product of quantities of the element in various condition states and the failure cost of the element, and TEV is the product of total element quantity and failure cost of the elements. Hence, it is important to determine the remaining useful quantities in each condition states of an element in the form of the extent and severity of defects (Roberts \& Shepard, 2001). The element condition index depends upon the types of distress present in each element. Generally, the most severe defect is chosen for determining the condition rating for that element. However, it would be more logical to consider the effects of all distress types present in an element affecting the structural integrity of 
a bridge (Wakchaure and Jha, 2012). Garry Sterritt and Steve Harris (2002) presented a set of guidelines to determine the condition ratings when multiple defects are present in an element. The guidelines utilized the following two scenarios: a dominant defect is present in the element in question, and there are interacting effects or no dominant defects are present. The first case is obvious where dominant defects governs the condition rating, whereas, in case of interacting defects the extent and severity is open to human interpretation. Different bridge inspection manuals use different guidelines to handle multiple defects. For example, PONTIS use smart flag element 358 for surface cracks and smart flag element 965 to handle shear cracks present in an element. Similarly, Ontario Structure Inspection Manual (OSIM, 2008) converts crack defects into surface area by assuming $4 \mathrm{~m}$ length of a crack is equivalent to $1 \mathrm{~m}^{2}$ areas of defect. This paper presents a novel approach for considering multiple defects suitable for automation in predicting element condition ratings.

\section{Image-Based Quantification of Distress Types}

Reinforced concrete bridges consist of several types of defects present in an element. The Norwegian graphic symbols list can be used to describe several damages in bridges as shown in Figure 1 (NCHRP, 2007).

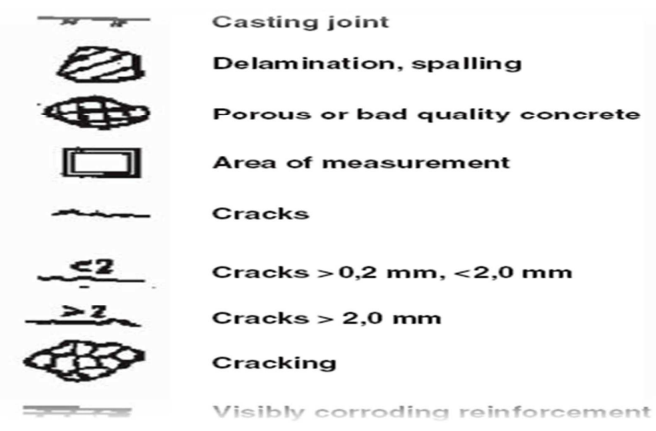

Figure 1: Norwegian graphic symbols for Damage in Concrete Structures

The figure explores five major types of defects present in concrete bridge structures. These defects are further classified in several sub-classes according to their severity and impact on structural integrity of bridge elements. The important factors to be considered in all classes of defects include the unknown size, shapes, and color, which add a great difficulty in automated defect detection techniques. One single algorithm for image analysis may not suffice to find an appropriate solution to automated condition assessment. Hence, it is necessary to develop different defect detection algorithms to capture different defects present in structural elements. Based on the quantification information, condition ratings need to be assigned according to the guidelines provided in inspection manuals. This paper considers the list of defects and elements weights summarized by Wakchaure and Jha (2012) to assign condition rating and hence the element condition index of bridges.

\section{METHODOLOGY}

The methodology encompasses a structured procedure for evaluating the element condition index based on digital image processing techniques as shown in Figure 2. This approach can be summed for all elements to get bridge condition index by assigning respective element weights (importance factors). 


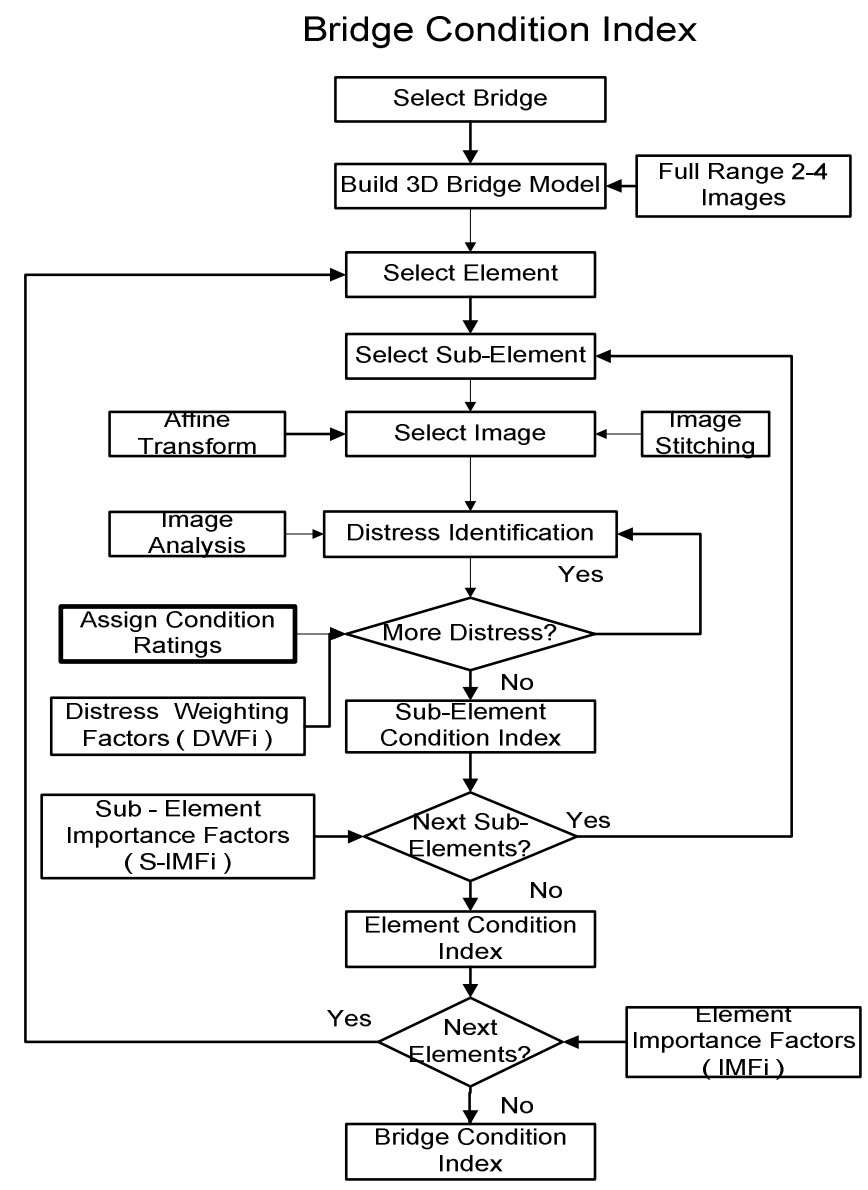

Figure 2 - The Proposed Methodology

The process starts with developing 3D model of bridges for easy visualization of inspection results. The elements and sub-elements were organized in a structured way and the images with surface defects were named according to their types to avoid confusion in the retrieval process. Before doing the image analysis for the quantitative metrics of the defects, the recorded images need to be corrected for noise, perspective, and parallax errors. These errors may distort the geometry of objects and any quantification thereafter will not be accurate.

\section{D visualization}

3D modeling provides a better understanding of an object and various features can be derived from such models. This work utilizes a direct method of photo projection to generate 3D models with help of Google Sketch up (2008). For better 3D models, 4 images are required at each four side of an object. However, a 3D model can be developed just from single image taken at 45 degree so that at least three corners can be seen from a single position. Figure 3 illustrates the result of the 3D modeling of a segment of a bridge deck which shows the overall dimensions and projected texture. 


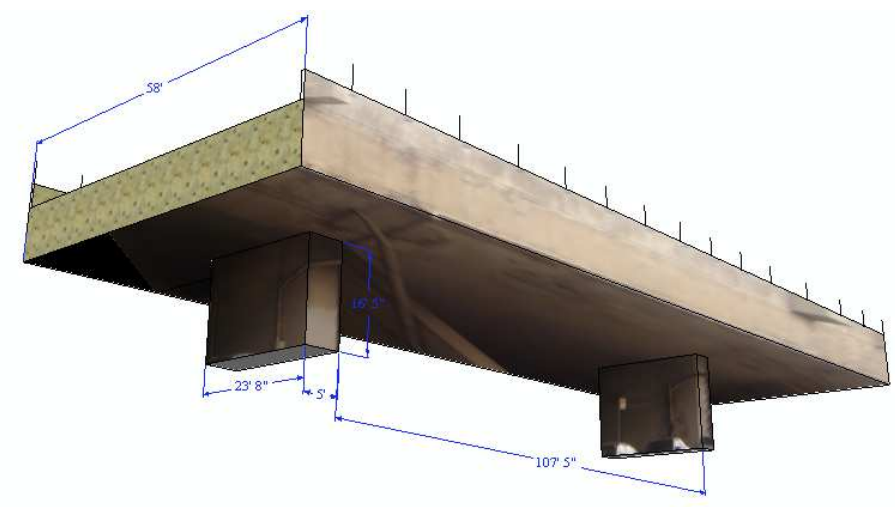

Figure 3 - Fly over pass at the intersection of street Selby and Greene near Lionel Groux Metro in Montreal

\section{Image Corrections}

A digital image is nothing more than a 2D projection of a 3D real world object. The effectiveness of digital image analysis highly depends upon the manner in which the 3D to 2D projections occurs (Solomon and Breckon, 2011). The image projections can be broadly classified in two parts: perspective and orthographic projections. The camera coordinate in perspective projection can be defined by Equation 1 .

$x=f * X / Z \quad \& \quad y=f * Y / Z$

where, a 3D real world coordinate is represented by $(X, Y, Z)$, a camera coordinate is given by $(x, y)$, and $f$ represents the focal length of a conventional camera. McRobbie (2008) showed that a single pixel in an image taken perpendicularly to the surface would represent a smaller area than the same pixel in an image taken at an angle. The orthogonal projection can be defined mathematically as

$X=m * X \& \mathrm{y}=\mathrm{m} * \mathrm{Y}$

where, $m$ is called the scaling factors. This projection is an affine transformation in which the relative geometric relationship of a set of objects is maintained. In practice, if we acquire images very close to scene, then it can be referred as orthography projection and is suitable for digital image analysis (Solomon and Breckon, 2011). However, in bridge inspection, it is not always possible to acquire images close to scene and we may need some transformation matrix to solve this problem. Figure 4 shows the work flow chart of an algorithm for achieving such transformation and successive corrections. The application needs to define a base image on which erroneous image will be projected. The algorithm has been applied to an original image as shown in Figure 5a and the result of corrected image is displayed in Figure 5b.

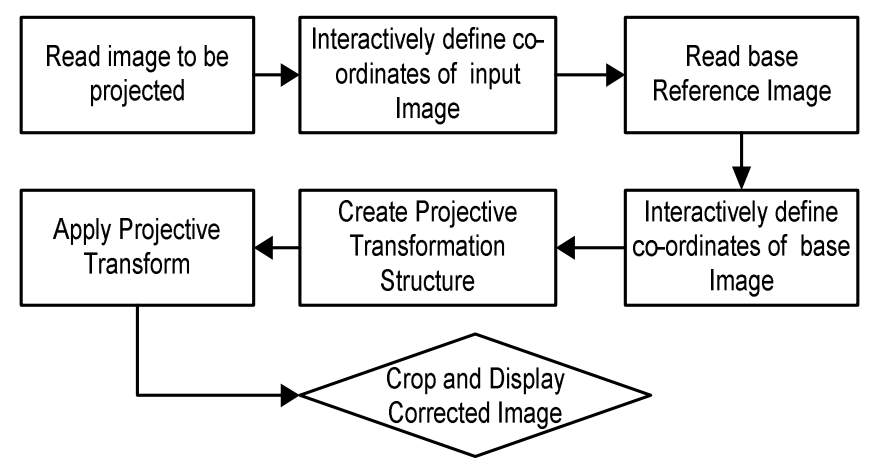

Figure 4 - Projective Transform Work Flow to get Corrected Images 


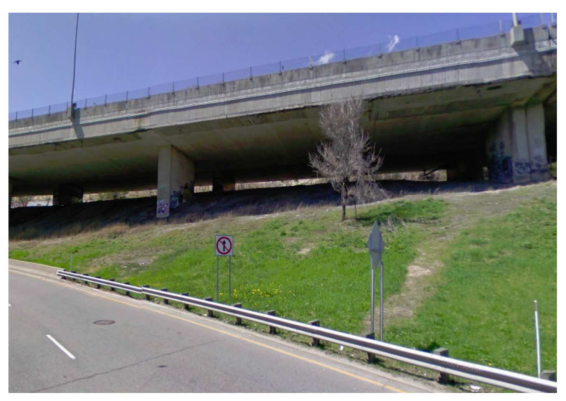

(a)

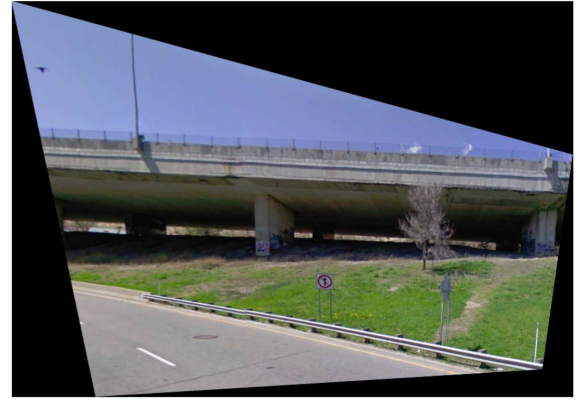

(b)

Figure 5 - Example of the geometric transformation: (a) acquired image with perspective error, and (b) the corrected Image

\section{Distress Quantification}

Reinforced concrete structures consist of a number of distress types as mentioned in Figure 1. Evaluation of $\mathrm{BCI}$ requires an estimation of the percentage of a particular defect that exists in a structural member. For example, the element condition rating for concrete decks and slabs without overlay as defined in PONTIS are as follows: 1 (no spall, Delaminations, and temporary patching), 2 (the combined distress is $2 \%$ or less of the total deck area), 3 (the combined distress is more than $2 \%$ but less than $10 \%$ the total deck area), 4 (the combined distress is more than $10 \%$ but less than $25 \%$ the total deck area), 5 (the combined distress is more than $25 \%$ the total deck area) (Minnesota Bridge Inspection Manual, 2009). Hence, it is important to determine the percentage of defects to assign an appropriate condition rating.

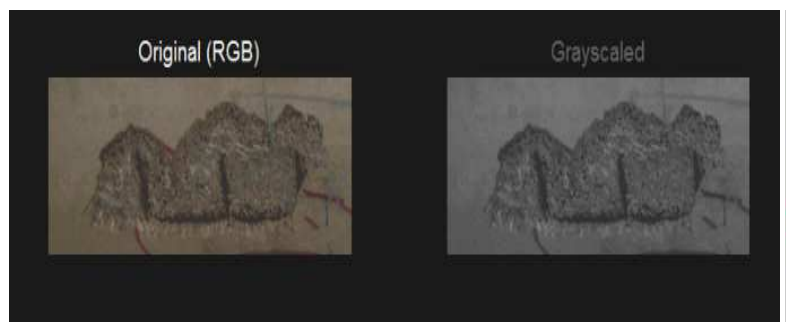

(a)

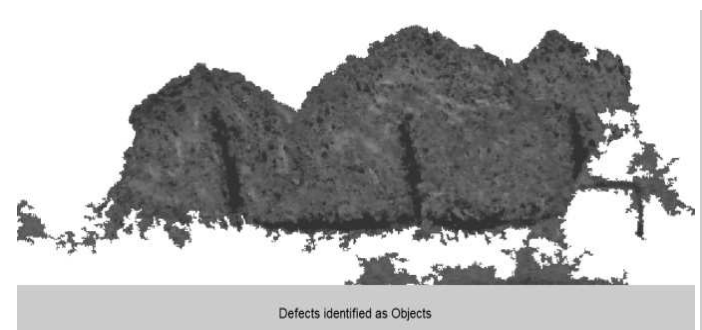

(c)

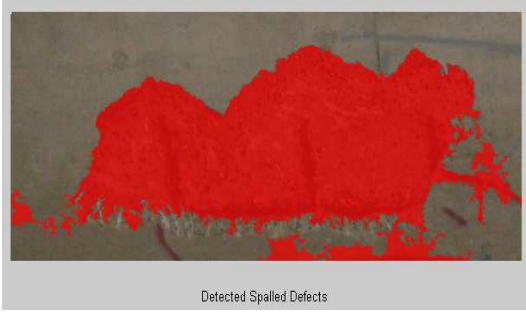

(b)

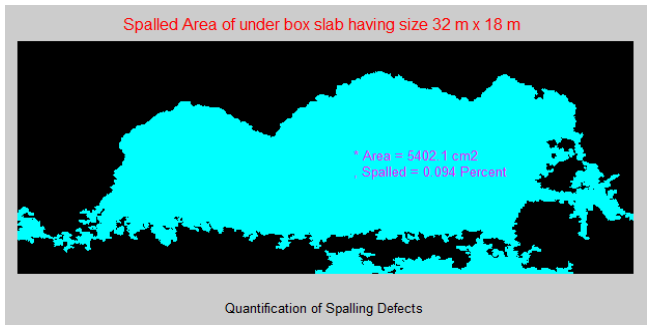

(d)

Figure 6 - Detection of the spalled area: (a) spalled area (in RGB and grayscale), (b) detected spalled area, (c) defects identified as an object, and (d) object leveling and quantification. 


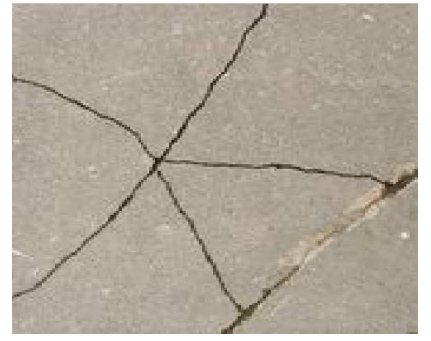

(a)

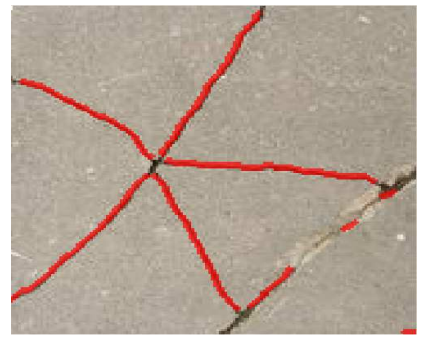

(c)

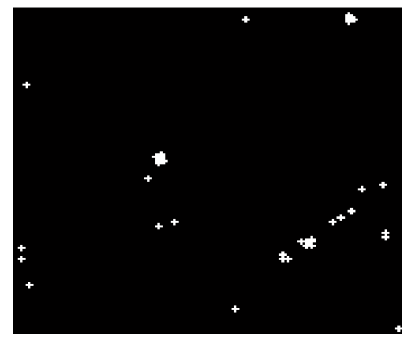

(b)

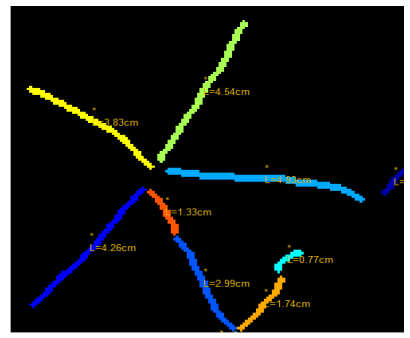

(d)

Figure 7 - Detection and quantification of cracks: (a) crack image (RGB), (b) branch points, (c) crack detection, (d) crack leveling and crack Lengths, and (e) Crack Widths, (f) A crack Scale

The proposed procedures for automated evaluation of defects such as spalling and cracks using digital image processing has been demonstrated here in Figures 6 and 7. The percentage spalling defects identification and quantification are explained in Figure 6 where as the procedure of retrieval of concrete crack properties is demonstrated in Figure 7. Performance evaluation of spalling segmentation process is tested by finding the false positive and false negative defects on 10 selected images from the overpass bridge deck shown in Figure 3. For the selected images, segmentation was corrected at $85 \%$ of the time with a false positive rate of $7 \%$ and a false negative rate of $8 \%$.

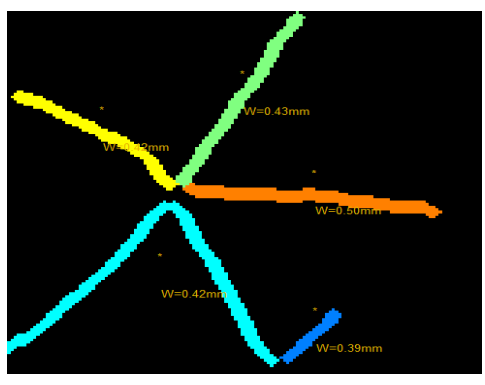

(a)

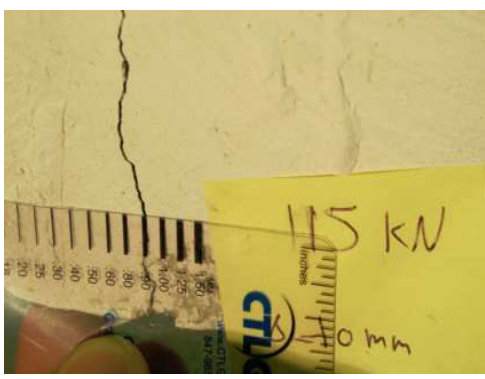

(b)

Figure 8 - Crack Width measurement: (a) automated evaluation, and (b) a crack scale

To check the accuracy of the developed algorithms, real crack images have been tested using a crack scale shown in Figures 8 and 9. To automate these processes, several functions have been developed in MATLAB environment: "SpallFcn" and "CrackFcn", which are utilized by a calling function named as "BatchProcessing" to handle a large number of similar images. A Graphical User Interfaces (GUI) shown in Figure 10 has been developed to enhance the usability of the implemented procedure. 


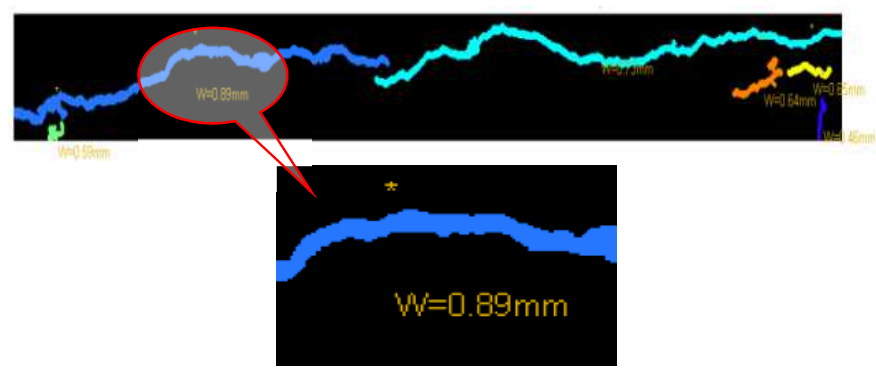

Figure 9 - Crack width measurement compared with the crack scale

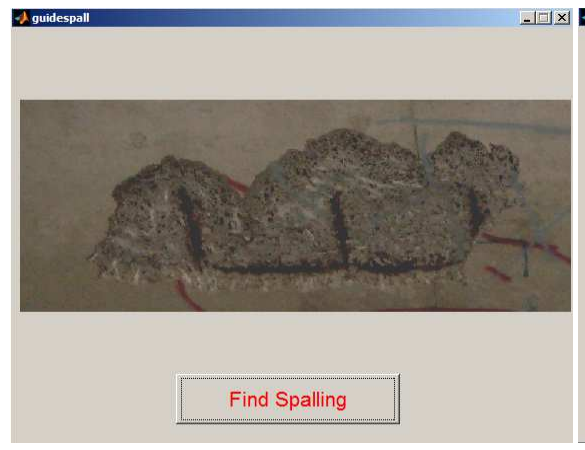

(a)

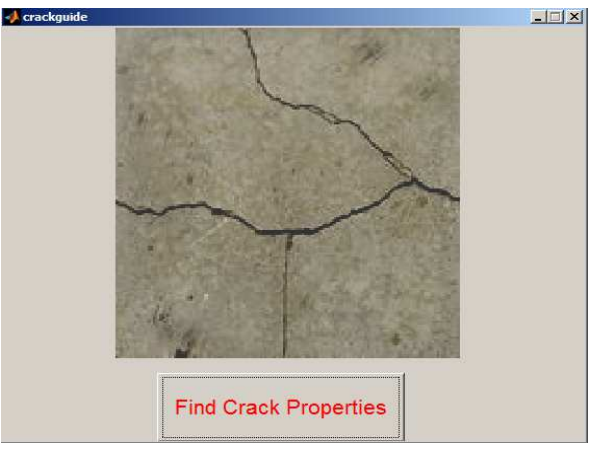

(b)

Figure 10 - GUI: (a) for Spalling, and (b) for Cracks

\section{Element Condition Index}

A set of equations $(3,4,5)$ are proposed here for the evaluation of the element condition index which utilizes the information of condition rating obtained from digital image processing.

$$
\begin{aligned}
& \mathrm{BCI}=\left\{\sum_{i=1}^{N} W(i) * \operatorname{ECI}(i)\right\} / \quad\left\{\sum_{i=1}^{N} W(i)\right\} \\
& \mathrm{ECI}(\mathrm{i})=\left\{\sum_{j=1}^{n} W(j) * S C I(j)\right\} / \quad\left\{\sum_{j=1}^{n} W(j)\right\} \\
& \mathrm{SCI}(\mathrm{j})=\left[\left\{\sum_{k=1}^{d} m * W(k)\right\} / \mathrm{d}\right] * 100
\end{aligned}
$$

where,

$\mathrm{BCI}=$ Bridge Condition Index, $\quad \mathrm{W}(\mathrm{i})=$ Element Weight Factors,

ECI (i) = Element Condition Index, $\quad W(j)=$ Sub-element Weight Factors,

SCI $(\mathrm{j})=$ Sub-element Condition Index,$\quad \mathrm{W}(\mathrm{k})=$ Distress Weight Factors,

$\mathrm{N} \quad=$ Number of Bridge Components, $\quad \mathrm{m}=$ Material Factors, Concrete $=1.0$,

$\mathrm{n} \quad=$ Number of Sub-element Components, $\mathrm{d}=$ Number of distress,

The weights of the elements and sub-elements, and distress weight factors were adopted from Table 3 based on the work of Wakchaure and Jha (2012). The predictions of condition rating based on various defects are done according to the guidelines provided in Table 5 (Wakchaure and Jha, 2012). The distress weight factors are calculated from Equation 6:

$$
\mathrm{Wk}=[1-(\text { Condition State } \#-1) *(1 /(\text { State Count }-1))]
$$


For the individual condition states (i.e. 1 to 5), the weights obtained from Equation 6 are 1, 0.75, 0.5, 0.25 and 0.0 , respectively. Table 1 shows the details of the weights for calculating the bridge condition index using the above equations for the selected bridge deck shown in Figure 3 whose overall size is $32 \mathrm{~m}$ by 18 $\mathrm{m}$. Here only two types of defects are identified (spalling and exposed reinforcements), and based on this information, the bridge condition index is found to be 90.85 which means that the element is in a good condition.

Table 1 - Evaluation of Bridge Condition Index

\begin{tabular}{|cccccccccc|}
\hline S.N. & Component & $\begin{array}{c}\text { Distress } \\
\text { Type }\end{array}$ & $\begin{array}{c}\text { Condition } \\
\text { State No. }\end{array}$ & Wk & SCI(j) & W(j) & ECI(i) & W(i) & BCI \\
\hline 1 & Substructure & & & & & & 100 & 26 & \\
2 & Pier & Nil & 1 & & 100 & 26 & & \\
$2 \mathrm{a}$ & Superstructure & Deck Slab & $\begin{array}{c}\text { Spalling } \\
\text { Exposed } \\
\text { Reinforce }\end{array}$ & 2 & 0.75 & 75.00 & 15 & & \\
& & 0.75 & & & & & \\
& & & & & & & & \\
& & & & & & & & \\
\hline
\end{tabular}

\section{IMPLEMENTATION AND RESULT}

\section{Implementation}

The proposed procedure implemented in the MATLAB R2012a environment on a Window Vista Enterprise 32 bit operating System. The desktop consists of Intel ${ }^{\circledR}$ Core TM 2 Duo CPU, E6550 @ 2.33 GHz.

Table 2 - Condition Assessment of a Deck Slab

\begin{tabular}{|cccc|}
\hline S.N. & $\begin{array}{c}\text { Area } \\
(\mathrm{m} 2)\end{array}$ & $\begin{array}{c}\text { Percentage } \\
\text { Defects }(\%)\end{array}$ & $\begin{array}{c}\text { Condition } \\
\text { Rating }\end{array}$ \\
\hline Deck Slab $(18 * 32)$ & 576 & & \\
Spalled & 5.2 & 0.92 & 2 \\
Exposed Reinforce & 5.2 & 0.92 & 2 \\
\hline
\end{tabular}

Table 2 shows the result of the condition assessment of a bridge deck slab. The defects identified are as spalling is $0.92 \%$ and exposed reinforced concrete is $0.92 \%$. Based on this information, the condition ratings assigned for these defects is 2 . The crack widths have been measured and compared to a crack scale. The results show that crack width obtained by the developed algorithms agrees with the crack width obtained by measuring with a crack scale. For practical purpose, crack width less than $0.3 \mathrm{~mm}$ is not recorded as it does not affect the integrity of structural elements significantly (Ryell and Richardson, 1972). By applying the proposed procedure of evaluating ECI for the selected bridge deck of area $32 \mathrm{~m}$ by $18 \mathrm{~m}$, the element condition index was found as 90.85 showing the element is in good condition. 


\section{LIMITATION AND FUTURE WORK}

This paper considered only few types of surface defects (spalling, cracks, and exposed reinforcement) and algorithms developed for automatic extraction of the properties of these defects. However, a particular bridge may contain various other types of defects and respective algorithms need to be developed for a complete analysis purpose. It is important to understand how various defects interact with each other so that the severity and extent of damage can be predicted with reasonable accuracy. If one defect interacts over others, the severity of the damage need is modified manually in this work. The automatic prediction of the condition state needs to be developed for all possible defects so that automated BCI evaluation is possible. The authors had previously worked on automatic prediction of scaling defects using neural networks (Adhikari, R.S., Moselhi, O., Bagchi, A., (2012).

An effective application of digital image processing in condition assessment of bridges needs to be explored in details. The paper uses both natural and artificial targets with a scale placed in the picture frame for image calibration purpose. For this reason, it is essential to determine the scaling factor in each image frame for defects quantification which poses difficulty in fully automating the process. Also, several pattern matching algorithms need to develop to classify the defects present in a given infrastructure. The authors are working towards developing a method based on multi-attributes neural networks to classify different defects considering various geometric features derived from color, texture, and spectral properties.

\section{CONCLUSION}

To enhance the current practice of asset management of bridges, a methodology for the evaluation of image-based element condition index considering several elements defects has been presented in this paper. The proposed method of automatic extraction of spalling and retrieval of crack properties from digital images taken from portable cameras has been discussed. However, digital images captured by a camera are influenced by perspective and parallax errors which make inaccurate quantification of defects. To solve this problem, the paper discusses the process of orthogonal transformation which maintains the geometric relationship of objects. The proposed approach is suitable for automation of the condition assessment of bridge deck using image analysis which eliminates the limitation of tradition visual inspection-based assessment such as subjectivity and qualitative information. The developed algorithms have been tested on various images and the results are satisfactory. For spalling defects, the selected segmentation is correct at $85 \%$ with $7 \%$ false positive and $8 \%$ false negative results for the selected bridge deck. The algorithm for extracting the crack properties showed acceptable evaluation of crack length and width compared with the result of a crack scale. Based on these defects quantification, condition ratings of defects assigned using guidelines in inspection manuals and literatures. Finally, all the data were plugged into excel sheet to determine element condition index which provides a useful tool for prioritizing bridges in a given bridge network.

Also, the proposed algorithms are developed in the form of GUI for convenient of end users. The $3 \mathrm{D}$ visualization of defects can enhance the traditional inspection procedure assisting the bridge inspectors about location and severity of defects in advance because it simulates the on-site visual inspection.

\section{ACKNOWLEDGEMENT}

The support of Concordia University Montreal Canada and Natural Sciences and Engineering Research Council of Canada (NSERC) is gratefully acknowledged. The contribution of all experts participated in this research is also warmly acknowledged.

\section{REFERENCES}

Abudayyeh O., Al Bataineh M., Abdel-Qader I, (2004), An imaging data model for concrete bridge inspection, Advances in Engineering Software, 35 (8-9), pp. 473-48. 
Adhikari, R.S., Moselhi, O., Bagchi, A., (2012), “Automated Prediction of Condition State doi: http://dx.doi.org/10.4017/gt.2012.11.02.153.00.

Austroads, (2002), "Bridge management systems - The state of the art.” Rep No - AP- R198, Australian and New Zealand Road Transport and Traffic Authorities, Australia

Bisby, L.A. and Briglio, M.B. (2004), ISIS Canada Educational Module No. 5: An Introduction to Structural Health Monitoring, Prepared by ISIS Canada, Page 3.

FHWA, (1991), Bridge Inspections Training Manual, Federal Highway Administration, Washington DC, July

FHWA, (1988), Recording and coding guide of the structure inventory and appraisal of the nations bridges, Federal Highway Administration, Washington DC.

Google sketch up, 2008, 3D for everyone, http://www.sketchup.com/intl/en/index.html

Hearn G., and Shim H., (1997), Integration of Non-destructive Evaluation Methods and Bridge Management Systems, Boston Massachusetts, August 25- 27.

McRobbie S., Lodge R., and Wright A., (2007), automated inspection of highway structures - Stage 2, PPR 255, Transportation Research Laboratory, UK

McRobbie S. G., (2008), automated inspection of highway structures 2008/09, Published Project Report PPR 412, Transportation Research Laboratory, UK

Minnesota Department of Transportation, BRIDGE INSPECTION MANUAL, (Version 1.8 - October, 2009.

MATLAB version R2012a, (2012), The Technical Computing Computer Software, the Math Works Inc

NCHRP, (2007) Bridge Inspection Practices a Synthesis of Highway Practice, Synthesis 375, and National Cooperative Highway Research Program.

Ontario Structure Inspection Manual (OSIM), (2008), Ministry of Transportation of Ontario, Policy, Planning \& Standard Division, Engineering Standard branch, Bridge Office, 2000 (Revised: Nov. 2003, April 2008).

Roberts, J.E. and Shepard, R. (2001) Bridge management for the 21st century, in Chase, S.B. Aktan, A.E., Health Monitoring and Management of Civil Infrastructure Systems, SPIE, Bellingham, WA, pp. $48-59$

Ryell, J. and B.S. Richardson, (1972), Cracks in Concrete Bridge Decks and Their Contribution to Corrosion of Reinforcing Steel and Pre-stressing Cables, Report IR51, Ontario Minis try of Transportation and Communications, Downs view, ON, Canada.

Sanjay S. Wakchaure and Kumar Neeraj Jha, Determination of bridge health index using analytical hierarchy process, Construction Management and Economics (2012) 30, 133- 149.

Sterritt G. and Harris S., Bridge Condition Indicators, Volumn 2, Guidance note on Bridge Inspection Reporting, WS Atkins Consultants Ltd, CSS Bridges Group, 2002

U.S. Army Corps of Engineers, (1993), Bridge Inspection Program FY 93 Routine Inspections, New England Division, 424 Trapelo Road, Waltham, MA, 02254-9149 